\title{
Effect of Neuroleptic Treatment on Polysomnographic Measures in Schizophrenia
}

Stephan F. Tayior, Rajiv Tandon, James E. Shipley, and Alan S. Eiser

To study the effects of neuroleptic therapy on sleep EEG variables in schizophrenia, as well as the clinical correlates of these variables, we performed polysomnographic (PSG) studies on 14 schizophrenic inpatients before and during neuroleptic therapy. Sleep continuity measures improved after 3 weeks of neuroleptic therapy, showing decreased sleep latency and improved sleep efficiency. REM latency increased with treatment, although half the patients continued to exhibit REM latencies less than $60 \mathrm{~min}$. Other sleep stages and measures of REM sleep (density, activity, number of periods) did not appear to change with nesuroleptic treatment. At baseline. REM latency had strong negative correlations with BPRS and SANS scores, but with 3 weeks of such treatment, this association disappeared. Further work is needed to distinguish direct medication effects from the effects of the changing clinical state on PSG measures.

\section{Introduction}

Polysomnographic (PSG) studies of schizophrenic patients have revealed a number of abnormalities, including reduced total sleep time and sleep continuity, reduced slowwave sleep, and shortened REM latency (for a recent review, see Keshavan et al 1990). However, the significance of these findings remains unclear.

One of the questions only partially addressed in the literature is how PSG findings change with treatment and phase of the illness. In a longitudinal study of 4-8 months duration of six schizophrenics (three on medication), Kupfer et al (1970) found that sleep abnormalities tended to occur during psychotic exacerbations and returned to near nonıal values as the psychotic state remitted. In investigations that have examined the effects of neuroleptics at dosages and durations that would be used in clinical practice, sleep continuity measures showed consistent improvement, as reflected by reduced sleep latency (Kaplan et al 1974), improved total sleep time (Jus et al 1968; Kaplan et al 1974; Gillin et al 1978; Keshavan et al 1989), greater sleep efficiency (Gillin et al 1977; Keshavan et al 1989), or fewer awakenings (ltil et al 1971a. 1971b).

Presented at the 46ih Annual Meeting of the Soxiety of Biological Psychiatry. New Orieans, Louisiana. May. 1991. From the Schizophrenia Program (SFT. RT) and Sleep Diagnostic and Research Prograsn (JES. ASE). University of Michigan Department of Psychiatry.

Address reprint requesis to Stephan F. Taylor. University of Michigan Medical Center. UH9C Box 0120. 1500 East Medical Center Drive. Ann Arbor. MI $48109-0120$.

Received March 28. 1991; revised June 6. 1991. 
Changes in sleep architecture exhibit less consistency, and differing nomenclature describing sleep staging make interpretation of the varying results difficult. Xaplan et al (1974) demonstrated a slight increase in the percentage of delta sleep in patients given chlorpromazine, while others report a decrease in some deep stages of sleep on haloperidol (Keshavan et al 1989; liil et al 1970) or high-dose fluphenazine (Itil et al 1971b). Other studies have found no differences (Gillin et al 1978; Jus et al 1968).

Alterations in the onset and character of REM sleep have been noted in schizophrenia and provide possible clues to pathophysiological mechanisms (Keshavan et al 1990; Kupfer and Eniers 1989; Tandon et al 1991). It is thereiore of some interest to learn how neuroleptic therapy alters REM. Kaplan et al (1974) have been the only group to report any change, which was a prolongation, of the onset of the first REM period, with chlorpromazine treatment. This study also found an increase in total REM activity and density, but not REM time. Some reports note increased REM density in schizophrenics treated with various neuroleptics (Jis et al 1968), but other investigators examining REM parameters have not found changes in REM activity or density after treatment with pimozide (Gillin et al 1978), thiothixene (Itil et al 1971a), fluphenazine (Itil et al 1971b) or haloperidol (Itil et al 1970). One recent report found decreased REM density after tre atment with haloperidol (Keshavan et al 1989). The different pharmacological profiles of these various neuroleptics and the preliminary nature of the work prevents one from drawing definite conclusions about the effect of neuroleptics on REM sleep.

We undertook the following sleep EEG study of schizophrenic patients, both before and after treatment with reuroleptics, to understand how PSG and clinical variables change with neuroleptic treatment. In order to further address pathophysiology, wo alsc examined correlations between these ciinical and physiological variabies.

\section{Methods}

We recruited 14 patients from our inpatient unit who met both DSM-III-R and SADS/RDC criteria for schizoptrenia. The c!rrent study represents a subset of a larger group of schizophrenic patients studied with sleep EEG while not receiving medication (Tandon et al 1991). An experienced research nurse admilistered the SADS. Patients who had a history of drug or alcohol abuse in the past 6 months or significant medical or neurological problems, including historical or clinical evidence of narcolepsy, were excluded from the study. Eligible patients gave informed consent before participating in the study.

Demographic characteristics of the 14 patients are listed in Table 1. Their average age was 31.1 years and their average duration of illness was 7.7 years. Six patients had never received neuroleptic medication previous to this study. Patients who had been receiving neuroleptic medication did not receive any psychotropic medication for a minimum of 2 weeks before the first night of sleep recordings.

In the drug-free state and at the time of the first PSG recording, the patients underwent clinical ratings by means of the 18-item Brief Psychiatric Rating Scale (BPRS) (Overall and Gorham 1962), and the Scale for the Assessment of Negative symptoms (SANS) (Andreasen 1983). After completion of the pretreatment PSG. neuroleptic therapy was begun with either haloperidol or thiothixene at clinically indicated doses (Table 1). Ten patients required treatment with antiParkinsonian medication (either benztropine or trihexyphenydil) for extrapyramidal symptoms. After an average of 24.4 days of neuroleptic treatment, the patients underwent two more nights of sleep EEG monitoring and the clinical ratings were repeated. in addition to the rating scales described, we also derived 
Table 1. Patient Characteristics and Treatment Data

\begin{tabular}{|c|c|c|c|c|c|c|c|c|}
\hline $\begin{array}{l}\text { DSM-III-R } \\
\text { Subtype }\end{array}$ & Age & Sex & Education & $\begin{array}{c}\text { Duration } \\
\text { III (yr) }\end{array}$ & Medication & $\begin{array}{l}\text { Chlorpronazine } \\
\text { Dose-- } \\
\text { Equivalent } \\
\text { (mg/day) }\end{array}$ & $\begin{array}{l}\text { Benztropine } \\
\text { Dose- } \\
\text { Equivalent } \\
\text { (mg/day) }\end{array}$ & $\begin{array}{c}\text { Trea:ment } \\
\text { Days }\end{array}$ \\
\hline 1 Undifferentiated & 34 & $\mathbf{M}$ & 13 & 13 & Thiothixene & 500 & 2 & 22 \\
\hline 2 Paranoid & 34 & $\mathbf{M}$ & 12 & 17 & Haloperidol & 750 & 4 & 44 \\
\hline 3 Paranoid & 28 & $\mathbf{M}$ & 12 & 7 & Thiothixene & 800 & 6 & 22 \\
\hline 4 Undifferentiated & 23 & $\mathbf{F}$ & 12 & 1.2 & Thiothixene & 600 & 3 & 23 \\
\hline 5 Undifferentiated & 44 & $\mathbf{F}$ & 12 & 4 & Haloperidol & 1650 & 0 & 20 \\
\hline 6 Undifferentiated & 22 & $\mathbf{M}$ & 12 & 1.5 & Thiothixenc & 600 & 1 & 32 \\
\hline 7 Paranoid & 29 & $\mathbf{F}$ & 17 & 1 & Thiothixene & 300 & 2 & 19 \\
\hline 8 Paranoid & 43 & $\mathbf{M}$ & 15 & 0.5 & Thiothixene & 400 & 1 & 29 \\
\hline 9 Partiuviu & 27 & $\mathbf{M}$ & 14 & 14 & Thiothixene & 400 & 2 & 27 \\
\hline 10 Undifferentiated & 33 & $\mathbf{M}$ & 15 & 10 & Thiothixene & 600 & 1 & 14 \\
\hline 11 Disorganized & 20 & $\mathbf{M}$ & 12 & 0.5 & Haloperidol & 495 & 0 & 19 \\
\hline 12 Paranoid & 45 & $\mathbf{M}$ & 14 & 24 & Haloperidol & 660 & 0 & 27 \\
\hline 13 Undifferentiated & 29 & 1.1 & 12 & 14 & Haloperidol & 1000 & 0 & 29 \\
\hline 14 Paranoid & 25 & $\mathbf{M}$ & 18 & 0.7 & Thiothixene & 400 & 4 & 25 \\
\hline Means & 31.1 & & 13.6 & 7.7 & & 654.0 & 1.9 & 24.4 \\
\hline
\end{tabular}

a positive-symptom score from the BPRS (Hedlund and Vieweg 1980), consisting of the summed scores for thought disorganization, suspiciousness, hallucinatory behavior, and unusual thought content.

On the days when the patients underwent sleep studies, daytime napping was not permitted. Polysomnography was performed while the patients slept in their own hospital beds, with the data transmitted via a multiplexing system (Telefactor Corp., West Conschocken, PA) to a nearby sleep laboratory control roum and recorded on a Grass Model 78B polygraph with band pass settings from 0.5 to $30 \mathrm{~Hz}$. The first night of recording involved a full montage PSG, including EEG (C3/A2), electrooculogram (EOG), submental electronyogram (EMG), respiratory monitoring, elestrocardiogram (ECG), and EMG of the ariterior tibialis muscle (to assess periodic leg movements). The first night was used to exclude any primary sleep disorder and to acclimatize the subjects to the recording conditions. Data from this night were not used in the analysis. A second pretreatment PSG utilized oniy EEG, EOG, and EMG for sleep-staging. The sleep study performed after initiation of neuroleptic therapy assessed sleep staging only. Subjects underwent two nights of sleep recording on neuroleptic medication that were averaged for data analysis, except for three patients in whom only one night was avaiiable.

Trained raters, blind to diagnosis and medication status, scored the sleep records according to modified Rechtschaffen-Kales criteria (1968). The following sleep continuity measures were assessed: net total time spent asleep (TSA), sleep latency (SL-time between lights out and first 10 min of stage 2,3 , or 4 sleep not interrupted by more than 2 min of stage 1 or $1 \mathrm{~min}$ of stage 1 plus $1 \mathrm{~min}$ of waking), arousals to wakefulness, time awake after the onset of sleep (wakefulness), sleep efficiency (TSA/total recording period), and sleep maintenance (TSA/SL-total recording). REM latency was taken as the time from sleep onset until the onset of the first REM period $3 \mathrm{~min}$ or more in duration, minus intervening time awake (RLMA). Other REM measures include REM activity (sum of visually scored eye-movement density from each 6-sec REM epoch on a 0-8 scale), 
Table 2. Sleep Parameters Before and After Neuroleptic Treatment 14 Patieni-Nights fir Pretreatment PSG and 25 Patient-Nights for Posttreatmert PSG)

\begin{tabular}{|c|c|c|}
\hline & $\begin{array}{l}\text { Pretreatment } \\
\text { mean }=S D\end{array}$ & $\begin{array}{l}\text { Posttreatment } \\
\text { mean }=S D\end{array}$ \\
\hline \multicolumn{3}{|l|}{ Sleep continuity } \\
\hline Sleep latency (min) & $65.8 \pm 45.8$ & $460 \pm 39.9$ \\
\hline Total time aslcep (min) & $304.9 \pm 75.0$ & $340.2 \pm 75.6$ \\
\hline Awake after sleep onset (min) & $24.1 \pm 25.2$ & $19.8 \pm 22.0$ \\
\hline Arousals & $5.6 \pm 3.1$ & $5.1=3.4$ \\
\hline Sleep efficiency $(\%)$ & $74.7 \pm 15.8$ & $82.7 \pm 8.3^{\circ}$ \\
\hline Sleep maintenance $(\{)$ & $92.2 \pm 9.1$ & $950=5.3$ \\
\hline \multicolumn{3}{|l|}{ Sleep architecture } \\
\hline Siage $1 \%$ & $14.8=6.9$ & $155=12.1$ \\
\hline Statc $2 \%$ & $54.7 \pm 9.8$ & $54.6 \pm 13.1$ \\
\hline Stage $3 \%$ & $3.9=4.7$ & $5.0=4.4$ \\
\hline Stage $4 \%$ & $4.9=9.9$ & $6.3 \pm 10.9$ \\
\hline Delta $z$ & $3.8=11.4$ & $11.3 \pm 13.7$ \\
\hline REM $\%$ & $21.7 \pm 6.1$ & $18.7 \pm 6.3$ \\
\hline \multicolumn{3}{|l|}{ REM sleep } \\
\hline REM latency, minus swake minutes & $39.4 \pm 42.3$ & $72.9=51.8$ \\
\hline REM perivis & $3.4 \pm 1.3$ & $3.1=1.0$ \\
\hline Total REM time (min) & $67.1 \pm 28.7$ & $65.6 \pm 28.0$ \\
\hline Total REM activity & $79.5=59.6$ & $88.5=65.3$ \\
\hline Totai REM density & $1.11=0.32$ & $1.24=0.52$ \\
\hline \multicolumn{3}{|l|}{ First REM period } \\
\hline Time $(\min )$ & $11.8 \pm 7.6$ & $18.4=12.5$ \\
\hline Activity & $12.6 \pm 8.0$ & $24.5=23.4$ \\
\hline Density & $1.06 \pm 0.48$ & $1.14 \pm 0.59$ \\
\hline
\end{tabular}

op 0.05 by paired e.test

total REM time, and REM density (REM activity/REM time). We examined these REM measures for the entire night and for the first REM period. Sleep architecture was designated as stages 1,2,3, and 4, and analyzed principally as a percentage of TSA. Delta percentage was the sum of stages 3 and 4 , taken as a percentage of TSA.

The PSG variables frequently exhibited nonparametric distributions, so we utilized nonparametric statistics (Wilcoxon signed rank test and Spearman rank correlation) as well as paired $t$-tests with appropriate data transformations to normalize the data (logarithmic, square root, or arcsin). Analysis of the clinicai rating scales was by Student's i-test.

\section{Results}

We found no difference between the first and second nights when the patients were on medication, so we have averaged these two nights for the analysis. Parametric and nonparametric tests gave virtually identical results, so we list the results oi the sleep EEG studies on Table 2 with the results of parametric testing. The major findings werc improved sleep continuity measures, such that the trested patients fell asleep earlier (46.0 versus $65.8 \mathrm{~min}, p<0.05$ ) and had a trend towards more total sleep time (340.2 versus 304.9 , $p=0.06)$, which also appeared as greater sleep efficiency $(82.7$ versus $74.7, p<0.05)$. 


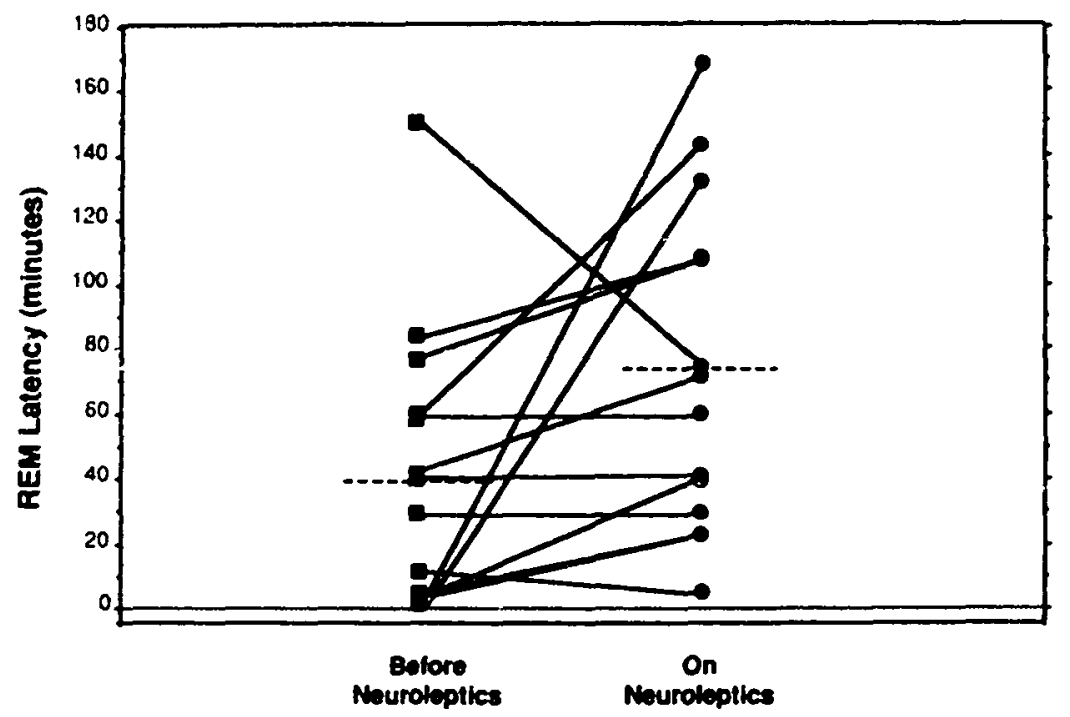

Figure 1. REM latency recorded in 14 schizophrenic patients before treatment ( 14 patient-nights) and after 3 weeks of neuroleptic therapy (25 patient-nights).

However, their sleep still appeared relatively fragmented, with no change in arousals, time awake after sleep onset. or sleep maintenance. Sleep architecture showed no changes with treatment.

Measures of REM sleep exhibited an increase in REM latency from 39.4 to $72.9 \mathrm{~min}$ $(p<0.05$ ), although 7 of the 14 patients still had REM latencies less than 60 min (Figure 1). Other REM measures did not show significant changes.

The clinical ratings showed a significant improvement, with total BPRS decreasing from $47.6 \pm 12.3$ (SD) to $32.4 \pm 6.1$ (df $=13, t=6.03, p<0.0001$ ). BPRS positive symptoms decreasing from $14.8 \pm 4.1$ to $9.2 \pm 2.0$ ( $\mathrm{df}=13, t=6.05, \rho<0.0001$ ) and SANS scores going from $12.4 \pm 5.1$ to $7.9 \pm 4.2$ ( $\mathrm{df}=13, t=6.12, p<0.0001$ ). Figure 2 displays scattergrams of the BPRS scores both before and on neuroleptics, demonstrating that except for three subjects, all subjects showed a decrease in symptom severity of at least 10 points.

In order to minimize the effects of outlicrs (persisting even after data transformation), we used Spearman rank correlations to correlate sleep variables with clinical rating scales. Table 3 lists the correlations at the $p<0.05$ level plus several other PSG variables of interest. The positive symptom subscale of the BPRS paralleled the total BPRS scores, so only total scores appear in Table 3. Because of the number of statistical tesis purformed, we have taken as significant only those comparisons at the $p<0.01$ leve F.E.t latency in the pretreatment PSG exhibited very strong negative correlations with in negative symptoms and total BPRS scores. However, this polysomnogram variabie measured after 3 weeks of neuroleptic treatment did not exhibit any significant correlations with clinical ratings ineasured after 3 weeks of treatment. Fisher $z$-transformations of the Spearman rank correlation coefficients ( $\mathrm{Zar} 1984)$ for REM latency with BPRS and SANS scores revealed a significant change in these associations with neuroleptic therapy. 


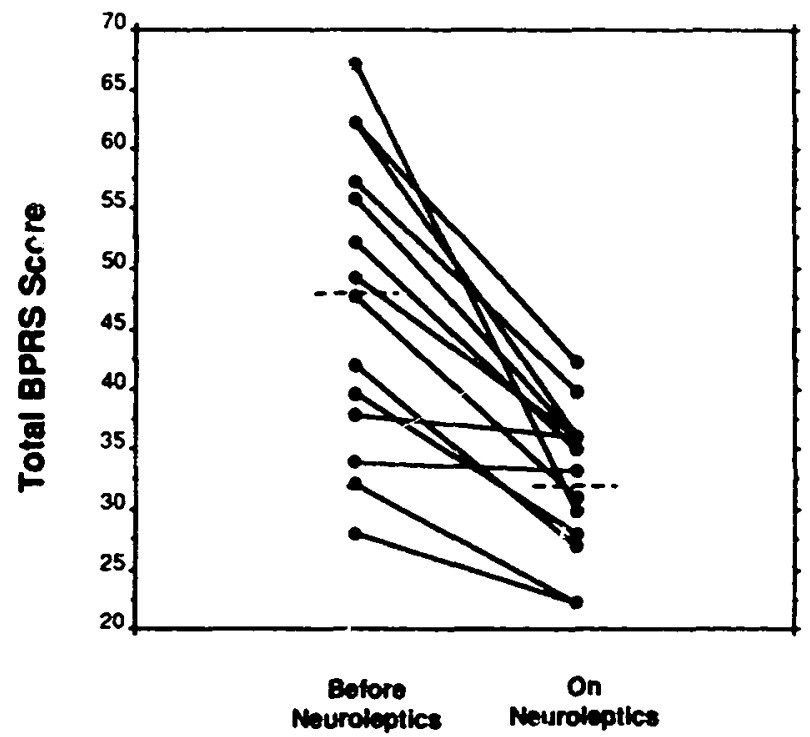

Figure 2. Brief psychiatric rating scale (BPRS) total scores for 14 patients at baseline and after an average of 24.4 days of neuroleptic treatme is.

\section{Discussion}

In this group of 14 schizophrenic patients treated with clinically indicated doses of neuroleptics, polysomnographic findings after approximately 3 weeks of treatment showed decreased sleep latency, improved sleep efficiency, and increased REM latency. Significant changes in sleep architecture were not evident in this sample.

Our findings of improved sleep continuity measures with neuroleptic treatment confirms previous reports in the literature (Jus et al 1968; Kaplan et al 1974; Gillin et al 1977, 1978; Keshavan et al 1989). Comparison between the improved sleep efficiency and shortened sleep latency in our patients with published values of normal subjects, as well as normal controls of similar ages from our database (Tandon et al 1991), suggest that

Table 3. Spearman Rank Correlations ( $r_{s}$ ) Between PSG Variables and Clinical Ratings

\begin{tabular}{|c|c|c|c|c|}
\hline \multirow[b]{3}{*}{ PSG variable } & \multicolumn{4}{|c|}{ Clinical Ratings } \\
\hline & \multicolumn{2}{|c|}{ Pretreatment } & \multicolumn{2}{|c|}{ On neuroleptics } \\
\hline & SANS & BPRS & SANS & BPRS \\
\hline Wakefulness & -0.23 & -0.30 & -0.01 & -0.19 \\
\hline Sleep latency & 0.20 & 0.24 & -0.25 & -0.22 \\
\hline Stage $1 \%$ & -0.67 & -0.35 & -0.10 & 0.05 \\
\hline Delta $\%$ & 0.34 & 0.16 & 0.47 & 0.30 \\
\hline REM iatency & $-0.72^{\circ}$ & $-0.7 \phi^{6}$ & -0.35 & $-0.31^{c}$ \\
\hline Total REM activity & 0.40 & 0.35 & 0.36 & 0.39 \\
\hline $\operatorname{REM} \alpha_{0}$ & 0.59 & 0.58 & 0.29 & 0.32 \\
\hline
\end{tabular}

-Significance of $r_{r}$ values: $p<0.01$.

Significance of $r_{i}$ values: $p<0.005$.

'Significance of change of $r$, values with texament: $p<0.01$. 
although these measures improve, they do not return to normal values after 3 weeks of treatment. Longer-term studies are required to assess whether these measures return to normal.

Poor sleep continuity is nonspecific and exists in many other psychiatric disorders, such as depression (Reynolds and Kupfer 1987), generalized anxiety disorders (Reynolds et al 1983), and obsessive-compulsive disorder (Insel et al 1982). At the most general level, the improvement in sleep may reflect a lessening of the "stress" of being in the acute phases of psychosis and hospitalization. Another possibility is that a direct medication effect, unrelated to pathophysiology, caused the improved sleep efficiency. This has not been reported in normals after acute administration of neuroleptics (Sagales and Erill 1975: Adam et al 1976), but the more restricted range of sleep efficiencies and a ceiling effect in normals might mask such a finding. Both haloperidol and thiothixene have $\mathrm{H}_{1}$-histaminergic antagonism, which is associated with increased sleep efficiency (Monti et al 1985). Even though disturbed sleep efficiency occurs in other disurders, it could still result from pathophysiological mechanisms hypothesized to underlie schizophrenia. Poor sleep efficiency has been found after the administration of dopamin: agonists (Cianchetti 1985; Nicholson et al 1989), consistent with the increased dopaminergic activity hypothesized to occur in schizophrenia, and after the administration of cholinesterase inhibitors (Sitaram et al 1977), consistent with the increased cholinergic activity also hypothesized $\because)$ occur in schizophrenic (Tandon ani Greden 1989). Further studies are necessary to distinguish between these hypotheses.

Although the mean and median REM latency of our schizophrenic patients increased, one half of our subjects continued to demonstrate latencies shorter than $60 \mathrm{~min}$. Several interpretations of this finding may be offered. Because sleep latency was also decreased, it is possible that the first REM period occurred at the same clock time in both pretreatment and posttreatment conditions. The presence of two different neuroleptics confounds inte:pretations of the findings, as well as the fact that ten of the subjects received anticholinergic medication-all of the nine patients taking thiothixene and only one of the five patients taking haloperidol. The patients receiving anticholinergics had longer REM latencies than those not receiving them. Cholinergic antagonists tend to delay the onset of REM sleep in normals, although this effect may diminish with repeated administration (Sagales et al 1976; Gillin et al 1989). Whe, we separately considered those patients receiving haloperidol, we did not find a significant increase in REM latency. This agrees with previous reports (Itil et al 1970; Keshavan et al 1989), but our smail number of subjects on haloperidol requires cautious interpretation.

The percentage of time in REM sleep showed a nonsignificant decrease with neuroleptic treatment. However, time spent in REM cues not maintain a consistent proportional relationship with total sleep time, tending to occur later in sleep (Nicholson et al 1989). Given that the patients slept more with treatment, REM percent should increase slightly. Analysis of all REM periods did not reveal a significant difference, but a larger sample may be necessary to demonstrate a reduction in REM time.

Clinical severity had a very strong correlation with shortened REM latency before treatment, such that shortened REM latency before treatment is associated with greater symptom severity as assessed by both SANS and BPRS scales. The association between severity and shortened REM latency has also been demonstrated in depressed patients (Kupfer et al 1983; Reynolds and Kupfer 1987). Such associations across patient groups suggest that shortened REM latency has a state component in general illness severity. 
We do not know whether the patients with shortened REM latency would exhibit normalization after more treatment, which was found in the early studies by Kupfer et al (1970), or whether a traitlike measure of abnormality would persist.

Significantly, none of the posttreatment clinical variables had any significant correlations with the posttreatment sleep study variables we examined, in spite of the fact that hese measurements were done within 1 or 2 days of each other. A dissociation occurred setween the mechanisms that linked early REM onset with clinical severity, even though ven of our patients continued to have abnormally shor REM latencies after 3 weeks is iseatment. With the design of this study, we cannot say whether or not medication hy self or specific pathophysiological change associated with the clinical change dissociated nese variables. The fact that treated patients had less range in their symptom ratings nust also be taken into account when considering this dissociation.

We regard our findings as preliminary and in need of replication with a larger sample size. The fact that we tested 20 PSG variables and found 3 correlations at the $p<0.05$ level raises the possibility of type $I$ errors and requires tentative conclusions. A more standardized neuroleptic regimen with neuroleptic blood levels would also strengthen the significance of future findings.

\section{References}

:jam K, Allen S, Carruthers-Jones 1, Oswald 1. Spence M (1976): Miesuridazine and human sleep. Br J Pharmacol 3:157-163.

indreasen NC (1983): The Scale for the Assessment of Negative Symptoms. lowa City, IA: The U'niversity of lowa.

anchetti $C$ (1985): Dopamine agonists and sleep in man. In Wauquier A. Gaillard JM. Monti JM. Radulovack M (eds). Sleep: Neurotransmitters and Neuromodulators. New York: Raven, pp 121-134.

Gillin JG, van Kammen DP. Post R, Bunney WE (1977): Effects of prolonged administration of pimozide on sleep-EEG patterns in psychiatric patients. Commun Psychopharmacol 1:225-232.

Gillin JC, van Kammen DP. Bunney WE (1978): Pimozide attentuates $d$-amphetamine-induced sleep changes in man. Life Sci 22:1805-1810.

Gillin JC. Ruiz C. Sutton L. et al (1989): The effect of scopolamine on slecp in depression and normal controls. Sleep Res 18:176.

Hedlund JL. Vieweg BW (1980): The Brief Psychiatric Rating Scale (BPRS): A comprehensive review. J Operat Psychiatn 11:48-65.

Insel TR. Gillin JC. Moore A. Mendelson WB. Loewenstein RJ. Murphy DL (1982): The sleep of patients with obsessive-compulsive disorder. Arch Gen Psychiarny 39:1372-1377.

Iit TM. Gannon P. Hsu W, Klingenberg H (1970). Digital computer analyzed sleep and resting EEG during haloperidol treatment. Am s Psychiaing 127:462-471.

lit TM, Hsu W, Klingenberg H. Gannon P. Holden M (197/a): Effect of thiothixene on digital computer sleep prints of schizophreric patients. Behav Neuropsychiarny 3:2-7.

Itil TM, Hsu W, Saletu B, Klingenberg H (197/b): Effects of fluphenazine hydrochloride on digital computer sleep prints of schizophrenic patients. Dis Nerv Syst 32:751-758.

Jus K. Kiljan A. Wilczak H, Kubacki A, Rzepecki J. Jus A (1968): Etude polygraphic du sommeil de nuit dans la schizophrenia. Ann Med Psychol (Paris) 126:713-725.

Kaplan J, Dawson S, Vaughan T, Green R, Wyan RJ (1974): Effect of prolonged chlorpromazine administration on the sleep of chronic schizophrenics. Arch Gen Psychiatry 31:62-66.

Keshavan MS. Reynolds CF. Brar J, et al (1989): Sleep EEG changes in schizophrenic during haloperidol treatment. Biol Psychiarry 25:181A. 
Keshavan MS, Reynolds CF, Kupfer DJ (1990): Electroencephalographic sleep in schizcphirienia: A critical review. Compr Psychiatry 30:34-47.

Kupfer DJ. Ehlers CL (1989): Two roads to rapid eye movement latency. Arch Gen Psychiatry 46:945-948.

Kupfer DJ, Wyatt RJ, Scott J, Snyder F (1970): Sleep disturbance in acute schizophrenic patients. Am J Psychiatry 126:1213-1223.

Kupfer DJ, Spiker DG, Rossi A, Coble PA, Ulrich R, Shaw D (1983): Recent diagnostic and treatment advances in REM sleep and depression. In Clayton PJ, Barret JE (eds), Treatment of Depression: Old Controversies and Now Approaches. New York: Raven, pp 31-51.

Monti JM, Pellejero T, Jantos H, Pazos S (1985): Role of histamine in the control of sleep and waking. In Wauquier A, Gaillard JM, Monti JM, Radulovack M (eds), Sleep: Neurotransmitters and Neuromodulators. New York: Raven, pe 197-209.

Nichelson AN, Belyavin AJ, Pascoe PA (1989): Modulation of rapid eye movement sleep in humans by drugs that modify monoaminergic and purinergic transmission. Neuropsychopharmacologv 2:131-143.

Overall JE, Gorham DR (1962): Brief psychiatric rating scale. Psychol Rep 10:799-812.

Rechtschaffen A, Kales A, Berger RJ (1968): A Manual of Standardized Terminology, Techniques, and Scoring System for Sleep Stages in Human Subjects. Bethesda, MD: National Institutes of Nervous Disease and Blindness.

Reynolds CF, Kupfer DJ (1987): Sleep research in affective illness: State of the art circa 1987. Sleep 10:199-215.

Reynolds CF. Shaw DH, Newton T. Coble PA, Kupfer DJ (1983): EEG sleep in outpatients with generalized anxiety: a preliminary comparison with depressed outpatients. Psychiatry Res 8:8189.

Sagales T. Erill S (1975): Effects of dopaminergic blockade with pimozide upon the EEG stages of sleep in man. Psychopharmacologia 41:53-56.

Sagalcs T. Erill S, Domiino EF (1976): Effects of repeated doses of scopolamine on the electroencephalographic stages of sleep in normal volunteers. Clin Pharmacol Ther 18:727-732.

Sitaram N. Mendelson WB. Wyatt RJ, Gillin JC (1977): The time-dependent induction of REM sleep and arousal by physostigmine infusion during normal sleep. Brain Res 122:562-567.

Tandon R. Greden JF (1989): Cholinergic hyperactivity and negative schizophrenic symptoms: A model of cholinergic/dopaminergic interactions in schizophrenia. Arch Gen Psychiatry 46:745753.

Tandon R, Shipley JE, Taylor SF, et al (1991): Sleep electroencephalographic abnormalities in schizophrenia: Relationship to positive/negative symptomatology and neuroleptic treatment. Arch Gen Psychiatry (in press).

Zar ZH (1984): Biostaristical Analysis, 2nd ed. Englewood Cliffs, NJ: Prentice-Hall, p ,20. 